\title{
Professionalization of social work in Germany: a reflection on the history of professional space development
}

\author{
H.-V. Bossong ${ }^{1}$, Z. H.-M. Saralieva' ${ }^{2}$, S. A. Sudjin ${ }^{2}$
}

${ }_{1}$ University of Duisburg-Essen, Germany

${ }^{2}$ Lobachevsky State University of Nizhni Novgorod, 7 University lane, Nizhni Novgorod, 603000, Russian Federation

DOI: $10.18255 / 2412-6519-2021-4-430-439$

Research Article

Full text in Russian

The professionalisation of social work is examined using Germany as an example. The main aspects of the process are explored: professional qualifications, content aspects of professional work, resources allocated and their control, as well as empirical and theoretical research in social work. The evolution of approaches to aid motivation from ecclesiastical and Christian traditions of love for one's neighbour to institutionalised aid within the functioning of welfare states is analysed. The dynamics of approaches to the definition of neediness in order to prevent the development of social parasitism is studied, the historical continuity of forms of work with socially deprived groups is shown. The professionalization of social work is considered in socio-historical context: its connection with protest movements of neo-Marxist persuasion in 1960 s and changes in the system of academic training of social work professionals with the introduction of Bologna system is analyzed. The material in this article is the result of many years of research, including participant observation by the authors.

This text is the latest and the last article by Professor Horst Bossong, one of Germany's leading specialists in social work, social policy and administration. The article summarizes the author's long-standing interest in the history and philosophy of social work, which reflects major milestones in the spiritual evolution and economic development of contemporary European societies.

Keywords: social solidarity, professionalisation of social work, social work in Germany, history of social work, philosophy of social work, management in social work

INFORMATION ABOUT THE AUTHORS

Боссонг, Хорст-Вернер | Dean of the Faculty of Education Sciences in 2004-2020

Саралиева, Зарэтхан Хаджи- Email: zara@fsn.unn.ru

Мурзаевна

Судьин, Сергей Александрович

Email: sudjin@mail.ru

(автор для корреспонденции)

Доктор социологических наук, доцент, заведующий кафедрой общей социологии и социальной работы факультета социальных наук

For citation: Bossong H.-V., Saralieva Z. H.-M., Sudjin S. A. Professionalization of social work in Germany: a reflection on the history of professional space development // Social'nye i gumanitarnye znanija. 2021. Vol. 7, No 4. P. 430-439. (in Russ.)

(C) Bossong H.-V., Saralieva Z. H.-M., Sudjin S. A., 2021

This is an open access article under the CC BY license (https://creativecommons.org/licenses/by/4.0/) 


\title{
Профессионализация социальной работы в Германии: рефлексия развития профессионального пространства
}

\author{
Х.-В. Боссонг ${ }^{1}$, 3. Х.-М. Саралиева², С. А. Судьин ${ }^{2}$
}

\author{
1университет Дуйсбург-Эссен, Германия \\ ${ }^{2}$ Национальный исследовательский Нижегородский государственный университет им. Н. И. Лобачевского, \\ Университетский переулок, д. 7, Нижний Новгород, 603000, Российская Федерация
}

DOI: $10.18255 / 2412-6519-2021-4-430-439$

УдК 316

Научная статья

Полный текст на русском языке

Рассматривается профессионализация социальной работы на примере Германии. В качестве основных аспектов процесса изучаются: профессиональная квалификация, содержательные аспекты профессиональной деятельности, выделяемые ресурсы и контроль за их расходованием, а также эмпирические и теоретические исследования в социальной работе. Анализируется эволюция подходов к мотивации оказания помощи: от церковных и христианских традиций любви к ближнему до институциализированной помощи в рамках функционирования социальных государств. Изучается динамика подходов к определению нуждаемости с целью воспрепятствования развитию социального паразитизма, показана историческая преемственность форм работы с социально депривированными группами. Профессионализация социальной работы рассматривается в социально-историческом контексте: анализируется ее связь с протестными движениями неомарксистского толка в 60-х гг. XX века и с изменением системы академической подготовки специалистов по социальной работе с введением Болонской системы. Материалы статьи представляют собой результат многолетних исследований, в том числе включенного наблюдения авторов.

Данный текст является последней статьей профессора Хорста Боссонга, одного из крупнейших немецких специалистов в сфере социальной работы, социальной политики и управления. Статья подводит своеобразный итог многолетнего авторского интереса к истории и философии социальной работы, в которых отразились основные вехи духовной эволюции и экономического развития современных европейских обществ.

Ключевые слова: социальная солидарность, профессионализация социальной работы, социальная работа в Германии, история социальной работы, философия социальной работы, управление в социальной работе

ИНФОРМАЦИЯ ОБ АВТОРАХ

Боссонг, Хорст-Вернер | Декан факультета наук об образовании в 2004-2020 гг.

Саралиева, Зарэтхан Хаджи- Email: zara@fsn.unn.ru

Мурзаевна Доктор исторических наук, профессор, профессор кафедры общей социологии и социальной работы факультета социальных наук

Судьин, Сергей Александрович Email: sudjin@mail.ru

(автор для корреспонденции) Doc. Sc. (Sociology), Associate Professor

Для цитирования: Боссонг Х.-В., Саралиева З. Х.-М., Судьин С. А. Профессионализация социальной работы в Германии: рефлексия развития профессионального пространства // Социальные и гуманитарные знания. 2021. Том 7, № 4. С. 430-439.

(C) Боссонг Х.-В., Саралиева 3. Х.-М., Судьин С. А., 2021

Статья открытого доступа под лицензией СС BY (https://creativecommons.org/licenses/by/4.0/) 


\section{Введение}

Рассуждения о принципе социальной солидарности наводят нас на мысль о том, что человеческий потенциал реализуется не только путем оказания помощи лицам, находящимся в нашем повседневном социальном окружении. Благодаря имеющимся технологиям и методам можно обеспечить необходимой помощью большое количество неизвестных нам клиентов, находящихся на значительном расстоянии от нас, что является одной из черт современных функционально высокодифференцированных обществ. Однако это может быть достигнуто только в организациях, работающих в рамках соответствующего законодательства и получающих необходимое финансирование.

На примере социальной работы можно продемонстрировать цивилизованное развитие процесса структурирования и профессионализации индивидуальной помощи и поддержки в особой сфере социальной солидарности. Этот процесс протекал не линейно, как это обычно бывает с социальными процессами, он далеко не всегда продумывался концептуально, а в большинстве случаев был спонтанным и рождался в ответ на возникающие чрезвычайные ситуации. Среди таковых - социальная реакция на распространение нищенства, уличной проституции и мелкой преступности в крупных городах. В любом случае о начальной профессионализации социальной работы в Германии в современном понимании этого слова можно говорить лишь с начала XX века.

Проследим процесс профессионализации социальной работы с использованием следующих показателей:

- профессиональная квалификация;

- профессиональная деятельность (формальная и содержательная);

- размещение ресурсов и контроль над ними;

- исследования в области социальной работы.

Используем эти четыре области, чтобы задать вопрос, в состоянии ли мы сегодня гарантировать в целом «идеальную», то есть современную, функционирующую систему социального обеспечения? Ответ и «да», и «нет». Но каковы основные проблемы, стоящие перед государством и различными сервисными компаниями и организациями, и какие корректировки могут и должны быть сделаны для обеспечения оптимального организованного ухода в долгосрочной перспективе? Этот вопрос касается наиболее важных элементов формирования профессионализма в интересах современной социальной работы. Какие навыки необходимы для соблюдения принципа социальной солидарности по отношению к социально незащищенным людям? Речь идет не просто о помощи, так как зачастую требуются совершенно новые форматы и методы, с которыми придется иметь дело при обучении, практике и исследованиях.

Солидарность в конкретной форме взаимопомощи, как хорошо известно, существовала всегда, в разных формах в зависимости от уровня развития и конкретного социального контекста; люди помогали друг другу еще и потому, что зависели друг от друга. Это всегда требовало морального поощрения. Так, например, нам известны наставления древнеримского философа Сенеки в начале первого века нашей эры: «Будем солидарны: мы родились для общины; наша община подобна арке из камней, которая рухнула бы, если бы камни не поддерживали друг друга, и они удерживаются ею» [1, с. 495]. Точно так же нам известны проповеди Василия Кесарийского в IV веке: «Ничего, - подчеркнул он, - так не свойственно нашей природе, как то, что мы живем в общении друг с другом, нуждаемся друг в друге и любим наших соплеменников. Но от 
того, что Бог ранее посеял в нас, Он, следовательно, требует плодов» [2]. В средние века богословские трактаты Фомы Аквинского (1225-1274) о милосердии и милостыне были особенно новаторскими; он писал: «Поскольку милосердие - это действие Божьей любви, то милостыня - это логическое действие любви Божьей через посредничество милосердия» [3, с. 255].

На этих трех примерах становится ясно, что практическая солидарность, забота и помощь являются не только общечеловеческими, но и религиозными обязанностями. В то же время мы видим, что до конца средневековья парадигма «добродетельного дарителя» была доминирующей. Сенека писал, что помощь «есть черта важного и ценного духа» [4, с. 103.]. А Фома учил: «Любовь Божия ... - это цель, на которую направлена любовь ближнего» [5, с. 146.], которая одновременно направлена «на искупление вины» [6, с. 256], то есть на спасение души дарителя.

Этот взгляд меняется в ранний современный период, когда число горожан, а вместе с ним и бедность и попрошайничество стремительно росли. На некоторых территориях более 50 \% жителей жили в относительной или абсолютной нищете. Следовательно, внимание теперь было направлено в первую очередь на нуждающихся: «настоящие» ли они или же это просто «профессиональные паразиты»? Парадигма добродетельного, благочестивого дарителя, господствовавшая до второй половины $\mathrm{XV}$ века, начала трансформироваться в парадигму злобного и ленивого получателя, к которому следует относиться с жесткостью, а не с милосердием. В центре общественного дискурса оказалась уже не мотивация дарителя, а характеристики берущего. Хотя религиозно мотивированный даритель все еще был нужен, с этого момента он должен был заботиться о том, чтобы его милостыня не доходила до ленивых и недостойных ее попрошаек.

Этика спонтанной помощи, которая функционировала на протяжении многих веков и функционирует в определенной степени до сих пор, была поставлена под сомнение обществом в целом и была признана дисфункциональной. Вместо этого в ходе дальнейшего развития, то есть продвижения функциональной дифференциации наших обществ, возникли новые формы солидарности, точнее, солидарность между чужими (Хауке Брункхорст) [7, с. 13-38]. Управление бедностью в интересах городского порядка, сегрегация нищих в пенитенциарные учреждения и в работные дома, особенно в начале XVII-XIX вв., постепенное, начиная с XIX в., предоставление гарантированных прав на льготы широким массам населения начинают играть все большую роль. Георг Зиммель охарактеризовал это как решающий сдвиг в парадигме. Речь идет прежде всего не о бедных, а о защите общества от бедности. Это имеет свои последствия. Если речь идет уже не о страданиях отдельного человека, а о благополучии общества в целом, доминирующими финансовыми инструментами становятся не добровольные пожертвования и даже не благотворительные фонды. Основными инструментами становятся общие налоги и обязательные отчисления на социальное обеспечение - это основа социального законодательства Бисмарка. Проявлением солидарности в отношении чужих людей стало достойное выполнение обязанностей по уплате налогов и отчислений - и не больше.

Уход и забота сегодня обретают новое звучание. Социальное благополучие, порядок и социальная интеграция в значительной степени реализуются как бизнес-модель, через успех в бизнесе социальных предприятий, которые служат общему благу, профессионально борясь с социальным и психологическим неблагополучием. В то же время это означает, что «помощь утратила прежний пафос» [8].

Так как же сегодня обстоят дела с социальной работой? 


\section{Профессиональная квалификация}

Как известно, повседневная помощь не является профессиональной деятельностью и не требует квалификации. Идея о необходимости профессионального образования в сфере заботы и помощи возникла в Германии еще в XIX веке, что не в последнюю очередь было обусловлено тогдашними успехами экономической науки. Заслуга в создании системы специализированного обучения практикам заботы принадлежит Алисе Саломон (1872-1948), создавшей в 1908 году в Берлине первую женскую социальную школу, что положило начало профессиональному образованию в сфере социальной работы. Она отмечала, что существует потребность в «тщательно проверенных методах», которые не только поддерживают нуждающихся в помощи, но и предлагают «эффективные», то есть постоянно работающие методы по избавлению от нужды [9, с. 155.]. Ее идеи ознаменовали формирование новой парадигмы заботы: «Любая забота <..> стремится к восстановлению экономической независимости, здоровья, способности вести ответственную жизнь. Но это только одна часть вопроса. Все сводится к другой цели. Ее можно назвать «развитием личности», средством для которого является сознательная и всесторонняя адаптация человека к его окружению, а также к конкретным потребностям и способностям. Это означает, что лицо, обеспечивающее уход, должно справляться с проблемами, порождаемыми как внутренним миром клиента, так и его социальным окружением» [10, с. 80.].

Становится понятно: забота - это сложный процесс, а не просто вынужденная адаптация клиента к социальным требованиям и нормам. Она включает в себя и формирование условий, которые затрудняют или, наоборот, облегчают социальную интеграцию, то есть мобилизуют все те ресурсы социального пространства, которые необходимы для успешной интеграции. Профессиональная помощь должна быть в равной степени сосредоточена на внутриличностных проблемах и конфликтах (а с другой стороны, ресурсах) клиента и на внешних угрозах и рисках. Именно учет психосоциального и внеличностного измерения стал основой современной парадигмы социальной помощи.

Конечно, многие идеи А. Саломон и других теоретиков государства всеобщего благосостояния начала XX века [11, с. 64-65] основаны на понятиях, которые в рудиментарных формах существовали на протяжении многих столетий. Это относится, например, к постулату «экономической самодостаточности» посредством работы в качестве убедительной альтернативы попрошайничеству, преступности и/или государственных трансфертов, а также к постулату о дотошной проверке личных средств. Оба эти постулата являлись важными условиями для предоставления помощи по крайней мере с XVI века. В частности, гуманист Хуан Луис Вивес (1492-1540), родившийся в Валенсии и проживавший в Брюгге (Бельгия), разработал первую систематическую теорию благосостояния и представил ее совету города Брюгге в 1526 году [12, с. 13-23]. Примечательны ясность и строгость его подхода: каждая городская администрация, писал он, - должна была составить регистр номеров и индивидуальных потребностей всех бедняков и постоянно его обновлять. На основе тщательной проверки средств в каждом отдельном случае каждому малообеспеченному человеку, который способен работать, но не может найти работу по собственному желанию, следует создать рабочее место на одном из ремесленных предприятий города. Если бедняк отказывается от этой работы, его следует к работе принудить, что станет примером и для других. Удивительно, но меры, применявшиеся в XVI веке, актуальны до сих пор: мы сейчас назы- 
ваем их первичной, вторичной и третичной профилактикой. Центральная идея в размышлениях Вивеса не утратила значимости и поныне: давать индивиду нужно то, что сделает его сильнее, а не то, чего он требует. Как официальная проверка нуждаемости в каждом отдельном случае, так и способность работать на регулярной основе, ведя благочестивый образ жизни, являются существенными предпосылками для ухода и заботы и по сей день. Но если индивид действительно не в состоянии работать и нуждается в серьезной помощи, то от социального работника требуется квалифицированное образование. Эту задачу и попыталась решить А. Саломон в своей женской социальной школе.

C тех пор социальное образование сильно изменилось. Если не принимать во внимание период нацистской диктатуры, можно выделить два этапа, которые сформировали актуальное состояние академической подготовки социальных работников в Германии: так называемое «движение 68 года» и Болонская реформа конца 90-х годов $\mathrm{XX}$ века.

«Движение 68 года» - это череда студенческих волнений и протестов, вдохновленных ренессансом марксистких идей в Западной Европе и США, носивших выраженную антиправительственную и критическую ориентацию. Так, в начале 1970-хгг. швейцарский социолог Вальтер Гольштейн и берлинский психолог Марианна Майнхольд критиковали социальную работу как орган контроля, надежное средство поддержания социального статус-кво капиталистической системы. Социальную работу обвиняли в дезинтеграции общества, в делении клиентов на «обычных» и «деклассированных», которые представлялись как жертвы эксплуатации, вынужденные приспосабливаться к окружающей действительности вопреки своим интересам и потребностям. Решением проблем виделось формирование класса подобных отверженных на основе осознания своих интересов.

Под шквалом этой критики, но прежде всего в связи с вопиющими недостатками в работе большинства учреждений в 1950-е годы и ростом жалоб со стороны клиентов профессиональное образование и практика социальной работы претерпели значительные изменения. Социальная работа стала университетской специальностью, подготовка была усилена блоком политических и общественных дисциплин. Образовательные науки заняли лидирующие позиции в формировании теории социальной работы. На протяжении многих лет особенно влиятельным был эмансипационный подход Клауса Молленхауэра из университета Франкфурта-на-Майне и Геттингена, а также концепция жизненного мира или повседневной ориентации, разработанная тюбингенским педагогом Хансом Тиршем. Развитие университетов с начала 1970 г. и появление молодых научных кадров, создание кафедр социальной работы по всей стране ознаменовали начало новой эпохи в развитии социальной работы как науки и учебной дисциплины.

После принятия в 1999 г. Болонской декларации о европейской реформе высшего образования произошел еще один важный, хотя и далеко не бесспорный шаг в сторону повышения качества академической подготовки социальных работников и социальных педагогов. В частности, модульная структура учебных программ и более конкретные учебные планы оптимизировали процесс обучения и сократили продолжительность учебных курсов. В настоящее время в 114 университетах немецкоязычного пространства существует в общей сложности 178 бакалаврских программ по социальной работе и социальной педагогике [13]; общее число студентов в последние годы в немецких университетах составляет от 70000 до 80000 человек; число студен- 
тов, зачисленных на первый курс, возросло за последние года с 16000 до 24000 человек. Количество выпускников варьируется от 12000 до 14000 человек [14], примерно 80 \% из них - женщины. В 2006 г. Профессиональный совет по социальной работе, в котором представлено большинство университетов, осуществляющих подготовку по данному направлению, впервые принял единые квалификационные рамки для обучения бакалавров и магистров в области социальной работы.

\section{Профессиональная деятельность}

На протяжении многих веков забота о бедных осуществлялась отдельными лицами и учреждениями, работающими на общественных началах, в первую очередь христианскими церквями и благотворительными ассоциациями. Социальная работа как профессиональная деятельность состоялась только в начале XX века. Предшественником этого была так называемая Страсбургская система 1905 г., которая, в свою очередь, пришла на смену так называемой Эльберфельдской модели, заключавшейся в разделении города на маленькие участки, в каждом из которых за призрение бедных отвечали конкретные люди, работавшие полный день на добровольных началах [15]. Предполагалось, что работники, занятые полный рабочий день, имеют больше опыта и смогут более последовательно осуществлять возложенные на них функции заботы о бедняках. Однако так думали не все. Влиятельный педагог Алоис Фишер (1880-1937), работавший в Университете Людвига Максимилиана в Мюнхене, резко раскритиковал созданный таким образом класс служащих, поскольку считал, что при определенных обстоятельствах «профессиональный подход приводит к усилиям, которые помогают и покровительствуют даже там, где собственные силы хотят и способны справиться с нуждой». С позиции сегодняшнего дня его страх нельзя сбрасывать со счетов: социальный бизнес живет во многом за счет конструирования социальных проблем и, как следствие, потребности в помощи. Другими словами, генерирование постоянного спроса является основой успеха.

Тем не менее в XX веке эпоха неоплачиваемой добровольной (почти) помощи подходит к концу, и большинство «помощников» теперь выполняют свою работу на профессиональной основе. Если в 1950 г. работники, занятые полный рабочий день, выполняли около трех миллионов часов работы в год, то пятьдесят лет спустя эта цифра уже достигла почти двух миллиардов часов [16, с. 40.]. С середины 1970-х годов мы наблюдаем значительный рост числа профессиональных социальных работников. Конрад Майер и Кристиан Шпатшек подсчитали, что в 1977 г. в (Западной) Германии на каждые 2777 жителей приходился один социальный работник, занятый полный рабочий день. В 2004 г. в объединенной Германии один социальный работник приходился уже на 720 жителей [17, с. 27.]. С тех пор ситуация на рынке труда для социальных работников продолжает улучшаться; в целом, по данным Немецкого совета экономических экспертов, в период с 1991 по 2015 гг. объем занятости в социальной сфере Германии увеличился на 77 \% (для сравнения: во всех секторах экономики за тот же период - на 11 \%). Поэтому неудивительно, что студенты, обучающиеся по специальности «Социальная работа», получают предложения от социальных организаций о будущем трудоустройстве буквально с первых семестров. При этом везде говорится о растущей нехватке квалифицированных кадров в сфере социальной работы. И последнее, но не менее важное: этот спрос позитивно отражается в законодательстве о коллективных договорах и дает заметный рост заработной платы в профессии. 
С конца 1970-х гг. произошли значительные изменения и в содержании образования, и в технологиях работы. Системный подход и консультирование, ориентированное на решение проблем, экспериментальные и реконструктивные методы нашли свое место в социальной работе. Широкое распространение получили медиативные процедуры, эмпауэрмент, кейс-менеджмент, социально-средовая ориентация и работа в социальных сетях. В целом можно сказать, что за последние сорок лет арсенал методов социальной работы был существенно расширен и диверсифицирован. Фактически развитие методов в последние десятилетия представляло собой в значительной мере компромисс между радикальными подходами идеологов 1968 г. и традициями психосоциального призрения, уходящими корнями в церковную благотворительность.

Этот компромисс сделал возможным технологический синтез и способствовал взаимному обогащению подходов. Прежде всего удалось акцентировать внимание на профессионализации социальной работы как части сферы услуг, которая преобладает в экономической структуре постиндустриальных обществ. Если повседневные потребности индивида в социальном и психологическом благополучии удовлетворяются сферой услуг, которые становятся все более индивидуализированными и приближенными к потребителю, то спектр этих услуг начинает расширяться и диверсифицироваться даже при сохранении права социальный работы на вмешательство в жизненную ситуацию клиента. Это, однако, относится к таким формам оказания услуг, которые организованы скорее рыночно, чем бюрократически. В силу этого неудивительно, что мы можем наблюдать возрождение интереса к критическим теориям 70-х гг. при анализе актуального состояния социальной работы, которая должна вернуть себе роль не рыночного, а политического субъекта. Здесь, возможно, упускается из виду то, что социальная политика имеет собственное дисциплинарное поле, отличное от профессионального пространства социальной работы. Интеграция в социальную политику чревата для социальной работы потерей собственной идентичности профессионального профиля. Следует задаться вопросом, какие предложения востребованы, почему и насколько устойчиво они работают? Существует потребность в эффективном управлении социальными услугами: эта тема на протяжении многих лет является предметом ожесточенных споров ученых и практиков.

\section{Использование ресурсов и контроль}

Около 30 \% ВВП ежегодно расходуется в Германии на общественно-политические цели, из них почти 50 млрд. евро тратится на меры и предложения по социальному обеспечению детей и молодежи (в 2018 г.). Только за последние десять лет расходы в этой области увеличились примерно в два раза, поэтому очевидно, что необходимо постоянно анализировать эффективность распределения ресурсов. На фоне стремительного роста муниципального и государственного долга в 1990-е гг. начали систематически использоваться инструменты контроля расходования средств. Эти усилия в целом были интегрированы в процессы реформирования или модернизации местных и государственных администраций.

Фактически речь шла о достаточно банальных требованиях. Например, предписывалось более четко, чем ранее, формулировать оперативные и стратегические цели проводимой политики для определения адекватности, типа и объема предоставляемого финансирования и последующего контроля. Процесс оказания услуг должен иметь конкретные и привязанные к результатам сроки, что делает возможным контроль отклонений от целевого результата. Текущие процедуры должны соблюдаться, 
документироваться и при необходимости корректироваться. В конце установленного периода дается взвешенная и критическая оценка проведенных работ. Только на основании этого должно быть принято решение о дальнейшей стратегии действий: будет ли продолжен проект, исправлен или прекращен. Существующие методы и приемы при всей их очевидности нередко горячо оспариваются. Классическая проблема «черного ящика» в процессе предоставления услуг, знакомая по теории принципала-агента, остается, таким образом, нерешенной и здесь. Одним из средств нормализации ситуации могло бы стать разумное использование сравнительного анализа, который в сочетании со строгими санкциями способствовал бы поиску передовой модели практики. Но и здесь критика часто бывает жесткой, довольно огульной и далеко не всегда улавливающей суть вопроса. Казалось бы, именно проблема «черного ящика» и массовая общественная критика заставляют многих руководителей отказываться от жесткого контроля. Вопрос, однако, в том, будут ли клиенты удовлетворены этим в долгосрочной перспективе?

\section{Исследования}

Начало исследований в области социальной работы можно датировать XVI веком. Они были посвящены изучению реального уровня жизни потенциальных получателей различных видов социальной помощи, что мы увидели в трудах Хуана Луиса Вивеса. Отчасти вдохновленные зарождающимися экономическими исследованиями в начале XIX века социальные науки на ранних этапах развития своей эмпирической практики тоже ставили своей целью детальное изучение сферы социальной работы. Пионерами здесь были в основном полевые исследователи в Англии и США. Благодаря своей работе 1845 года «Положение рабочего класса в Англии» к пионерам социологического подхода к проблеме бедности может быть причислен и Фридрих Энгельс [18]. Следует упомянуть, конечно, и Георга Зиммеля, который посвятил 7-ю главу своей «Социологии» (1908) теме бедности и недостаточности мер социальной политики [19]. Среди других авторов необходимо выделить Кристиана Джаспера Клумкера [20] и Алису Саломон. Пауль Наторп (1899) [21] и до него Карл Магер (1844/1845) [22] занимались темой социальной педагогики, но в первую очередь их работы были нацелены на инновации в области общей педагогики или школьного образования.

С конца 1940-х до начала 1960-х годов в особом почете были эмпирические исследования, нацеленные на решение конкретных проблем. Практика «ползучего эмпиризма», пришедшая из США, оказалась очень востребованной. С 1990-х годов неуклонно растет популярность как эмпирических, так и теоретических исследований. С методической точки зрения отметим преобладание качественных методов, что обусловлено, с одной стороны, спецификой предмета социальной работы, а с другой инерционностью профессионального сообщества, которое пока еще трудно убедить в необходимости использования количественных методов. Тем не менее в целом результаты исследований в настоящее время являются важным элементом функционирования системы социальной работы.

\section{Ссылки / References}

1. Lucius Annaeus Seneca. Briefe an Lucilius (Liber Quintus Decimus) // Lucius Annaeus Seneca. Philosophische Schriften. Band 4. Darmstadt, 1984.

2. Basilius von Caesarea. Ausgewählte Schriften. Kempten, 1877. 
3. Thomas von Aquin. De Beneficentia, Quaestio XXXII // Thomas von Aquin. Summa Theologica. Band 17a. Heidelberg u.a., 1959.

4. Lucius Annaeus Seneca. Über die Wohltaten (De Beneficiis) // Lucius Annaeus Seneca. Philosophische Schriften. Band 5. Darmstadt, 1989.

5. Thomas von Aquin: De Praeceptis Caritatis, Quaestio XLIV // Thomas von Aquin. Summa Theologica. Band 17b. Heidelberg u.a., 1966.

6. Thomas von Aquin. De Eleemosyna; Quaestio XXXII // Thomas von Aquin. Summa Theologica. Band 17a. Heidelberg u.a., 1966.

7. Liebsch B. Originäre Solidarisierung versus Pseudo-Solidität // Jahrbuch für christliche Sozialwissenschaften. Münster, 2007. Band 48, S. 13-38.

8. Luhmann N. Formen des Helfens im Wandel gesellschaftlicher Bedingungen // Otto, H. U., Schneider, S. (Hg.) Gesellschaftliche Perspektiven der Sozialarbeit. Band 1. Neuwied u. Darmstadt, 1973.

9. Salomon A. Leitfaden der Wohlfahrtspflege. Leipzig u. Berlin, 1921.

10. Salomon A. Schriften. Band 3.1926 // Kuhlmann, C. (Hg.): Geschichte der Sozialen Arbeit II. Schwalbach, 2008.

11. Vgl. vor allem: Klumker, Chr. J. Methodik. 1911 // Schriften zur Jugendhilfe und Fürsorge. Frankfurt/M., 1968. S. 64-65.

12. Kuhlmann C. Geschichte Sozialer Arbeit II. Eine Einführung für soziale Berufe. Textbuch. Schwalbach/Ts.: Wochenschau Verlag, 2008.

13. Sozialarbeit Studium. 196 Studiengänge // StudiScan. URL: https://www.studierenstudium.com/studium/Sozialarbeit (дата обращения: 14.06.2020).

14. Sozialwesen: Sozialarbeit und Sozialpädagogik // Universität Duisburg-Essen. URL: https://www.uni-due.de/isa/fg_sozial_gesund/sozialwesen/sozialwesen_hs_frm.htm (дата обращения: 14.06.2020)

15. Павлова И. П. Эльберфельдская система социальной помощи неимущим: от добровольчества к профессионализму // Журнал исследований социальной политики. 2016. Т. 14. № 3. С. 363-376.

16. Ottnad A. u.a. Zwischen Markt und Mildtätigkeit. Augsburg, 2000.

17. Maier K. Spatscheck, Chr. Arbeitsmarktchancen für SozialarbeiterInnen // Sozial extra. 2004. Heft 11.

18. Энгельс Ф. Положение рабочего класса в Англии // К. Маркс и Ф. Энгельс. Сочинения. Изд. 2-е. Т. 2. М.: Политиздат, 1955. С. 231-517.

19. Simmel G. Soziologie. Leipzig: Duncker \& Humblot, 1908.

20. Klumker Chr. J. Methodik // Schriften zur Jugendhilfe und Fürsorge. Frankfurt, 1968.

21. Наторп П. Избранные работы / Сост. В. А. Куренной. М.: Территория будущего, 2006. 384 c. // Высшая школа экономики. URL: https://www.hse.ru/data/2010/03/07/1231520277/Наторп\%20Пауль.\%20Избранные\%20p аботы.\%202006.pdf (дата обращения: 17.11.2021).

22. Karl Mager. Die deutsche Bürgerschule. Schreiben an einen Staatsmann. Stuttgart, 1840. 268 s. 